\title{
28 Research Square \\ Longitudinal Analysis of Influencing Factors of Problematic Smartphone Use in Preteens
}

Hyunmi Son ( $\nabla$ hmson@pusan.ac.kr)

Pusan National University

Jungim Yun

Pusan National University

Gyumin Han

Pusan National University

\section{Research Article}

Keywords: behavior, addictive, preteen, smartphone

Posted Date: March 1st, 2022

DOI: https://doi.org/10.21203/rs.3.rs-1356627/v1

License: (1) This work is licensed under a Creative Commons Attribution 4.0 International License.

Read Full License 


\section{Abstract}

Background: In the socially distanced era triggered by the coronavirus disease 2019 pandemic, there has been a surge in online activities across children's and adolescents' lives. Increased smartphone use by children and adolescents places them at higher risk of overdependence.

Methods: The purpose of this study, using secondary data from the $10^{\text {th }}$ to $11^{\text {th }}$ wave of the Panel Study on Korean Children, was to longitudinally investigate problematic smartphone use in preteens and to comprehensively understand the effects of variability and diversity in preteen development on excessive smartphone use. STATA/BE 17 was used to analyze the panel logit model. Among the 1,286 participants aged 9-10 from the Panel Study on Korean Children, 342 with complete responses (from the parent, child, and school teacher) were selected as the subjects of this study.

Results: The size of the risk group for preteens' problematic smartphone use showed a trend of increasing from 126 in 2017 to 149 in 2018. Factors influencing smartphone overdependence included the authoritative parenting behavior, permissive parenting behavior, child's externalizing problems, peer communication, and parental supervision. Factors related to parents and peers, as well as their own characteristics, had a complex effect on preteens' problematic smartphone use.

Conclusions: To reduce preteens' smartphone overuse, it is necessary to avoid permissive parenting behaviors and to increase parental monitoring of this population. Interventions should be conducted that focus on reinforcing parenting behaviors that respect preteen's opinions and set rules together, and strengthen preteen's communication with their peers.

\section{Background}

Worldwide, 6.4 billion individuals use smartphones, and the smartphone distribution rate has reached $78 \%$ [1]. Smartphones can be used without time and spatial restrictions, making them convenient; however, excessive use of and dependence on smartphones may cause physical and psychological problems [2, 3]. As smartphones become increasingly accessible even to lower age groups, their excessive use by children and adolescents has become a major health issue.

Approximately $30.2 \%$ of children and adolescents aged $10-19$ are at risk for smartphone overdependence. This rate is the highest among all age groups, indicating that smartphone overuse is a serious health issue in adolescents [4]. Problematic smartphone use causes serious problems in the physical and mental development of children and adolescents, including sleep disorders [5], decreased empathy and difficulties in academic achievement and adjustment to school life [6]. Additionally, it may induce aggression, causing problematic behaviors such as deviance and delinquency $[7,8]$.

In particular, the excessive use of smartphones is steadily increasing in preteens [9]. The preteen years, identified as the 9-12 age group, are a transitional period of development from children to adolescence [10]. As people generally own their first smartphones in their preteens, this is a period of active 
smartphone use [4]. Additionally, preteens spend most of their time at school and with their peers, away from their parents and families. This increased time away from home may lead to decreased parental management and regulations [11]. Inappropriate habits developed during the preteens tend to lead to problems in adulthood. Therefore, understanding the mechanisms of preteens' smartphone overuse is essential to prevent excessive smartphone use in adolescents and adults.

While preteens continuously undergo cognitive, social, and emotional development [12], they also demonstrate emotional instability, high impulsivity, and lack of self-regulation [13]. Moreover, prominent in preteens' behavior are the effects of parental absolute control, characteristic of childhood, and those of indirect parental control, characteristic of mid-adolescence [14]. During the preteen period, it is important to form peer groups and develop new bonds. As preteens enter adolescence, expectations and demands related to learning activities and adaptation to school environments gradually increase [11]. Therefore, to resolve the problematic behaviors of preteens, it is essential to consider interpersonal factors between parents and peers, including children's characteristics based on changes in life patterns and developmental characteristics during this period.

Factors affecting problematic smartphone use in preteens include immature defense mechanisms and emotion regulation ability, judgment disorder, aggression, and lack of self-control $[15,16,17,18]$. In addition, academic problems are an important factor [19]. Previous studies on preteens' peer relationships have showed that higher peer attachment reduces overdependence on smartphones [20]. However, other studies have revealed opposite results [21].

Regarding the parental influence, positive parenting behaviors based on affection and interest [22, 23, 24], as well as a high degree of parent supervision over what child do and with whom they spend time, have been shown to be protective factors for problematic smartphone use [25]. On the contrary, some studies have shown that the higher the parental overprotectiveness or interest [26]. and parental attachment [27]. the higher the risk of preteens' problematic smartphone use.

Although the preteen years are a period of rapid changes in development needs and the surrounding environment, most studies have employed cross-sectional designs, limiting the exploration of the influencing factors of problematic smartphone use. As excessive smartphone use has become a major health problem for children and adolescents, identifying the related factors in preteens may help prepare prevention and early intervention strategies. Therefore, the purpose of this study was to identify the factors affecting smartphone overuse through a longitudinal approach that reflects the changes in preteens' growth and development. Furthermore, we aimed to identify the protective and risk factors for preteens' problematic smartphone use through a comprehensive assessment of child, parent, and peer factors.

\section{Methods}

Design 
This longitudinal study is a secondary analysis of data from the $10^{\text {th }}$ to $11^{\text {th }}$ wave of the Panel Study on Korean Children (PSKC).

\section{Setting and Subjects}

In the PSKC, children born at medical institutions nationwide in 2008 will be followed up until 2027 to track their growth and development. The PSKC uses stratified multi-step sampling, and data are collected by dividing the whole country into six regions. The number of births per year in each region is proportionally allocated. PSKC data were acquired from a balanced panel surveyed at regular intervals. The subjects of this study participated in the 10th and 11th years of the PSKC, which started the investigation on smartphone addiction among preteens. And among 1,286 children aged 9-10 who responded parents, children, and school teachers 342 people who answered all the questions were selected as the subjects of this study.

\section{Measurements}

Sociodemographic and smartphone-related characteristics. Sociodemographic characteristics included gender, residence area, household monthly income, and mother's educational level and employment status. Smartphone-related characteristics included whether preteens owned a smartphone and the duration of daily smartphone use.

Smartphone addiction. Smartphone addiction was assessed using the K-Scale for Adolescent Observers, an internet addiction diagnostic scale provided by the Internet Addiction Response Center (iapc.co.kr) of the National Information Society Agency (2019) [28]. The scale was modified for use in preteens. Answered by the subjects' mothers, the instrument consists of 15 items: five items on factor 1 (daily life disorder), four items on factor 3 (withdrawal), four items on factor 4 (tolerance), and two items for an unclassified factor. The questionnaire consisted of evaluated on a four-point Likert scale from "not at all" (1 point) to "a great deal" (4 points), with higher scores indicating a greater risk of addiction. Using the total score and summation score for each factor, subjects were classified as general users, potential-risk users, and high-risk users.

General users had a total score of $<27$ points, and the criteria for each factor were as follows - factor $1:<$ 12 points, factor $3:<10$ points, and factor $4:<9$ points. Potential-risk users had a total score of 28-29 points with a score of $>13$ points for factor $1,>11$ points for factor 3 , and $>10$ points for factor 4 . Lastly, high-risk users had a total score of $>30$ points, with a score of $>14$ points for factor $1,>12$ points for factor 3 , and $>11$ points for factor 4 . Potential- and high-risk users were classified as risk users.

\section{Child factors.}


Overall happiness. This variable was measured using the Millennium Cohort Study Child Paper SelfCompletion Questionnaire (2008) [29]. Overall happiness indicated happiness in each area of daily life (academics, appearance, family, friends, school life). The questionnaire consisted of six items evaluated on a four-point Likert scale from "not happy at all" (1 point) to "very happy" (4 points). A higher score indicated higher overall happiness.

Selfesteem. This variable was evaluated using five items from the Millennium Cohort Study, which, in turn, were taken from Rosenberg's (1965) [30]. 10-item Self-Esteem Scale according to the children's age [29]. In the PSKC, some items were modified to improve comprehension. The items were evaluated on a five-point Likert scale from "not happy at all" (1 point) to "very happy" (5 points). A higher score indicated higher self-esteem.

Strengths and difficulties. This variable was evaluated using the Korean translation of the Strengths and Difficulties Questionnaire for teachers available online [31]. The subjects' teachers provided the necessary data by responding to the online questionnaire. In the provided translations, two items were partially revised to suit the context following discussions with PSKC researchers. For example, 'stealing from home, school, or somewhere' was partially modified to 'stealing things at home, at school, or somewhere'. Children's strengths and difficulties may be divided into prosocial behavior and total difficulties. Total difficulties consisted of internalization difficulties (emotional symptoms, peer problems) and externalization difficulties (behavioral problems, hyperactivity/inattention). The tool consisted of 25 items evaluated on a four-point Likert scale from "not at all" (1 point) to "a great deal" (4 points).

School adjustment. This variable was evaluated using a tool developed by Ji and Jeong [32]. Data were collected from the subjects' teachers through the online questionnaire. The tool consisted of 35 items in four sub-domains: 11 items on adjustment to school life, 11 items on adjustment to academic performance, eight items on peer adjustment, and five items on teacher adjustment. Each item was evaluated on a five-point Likert scale from "strongly disagree" (1 point) to "strongly agree" (5 points). A higher score indicated greater school adjustment.

\section{Peer factors.}

Peer attachment. This variable was assessed through a nine-item questionnaire used by extracting only the peer attachment scale from Armsden and Greenberg's (1987) Parent and Peer Attachment Scale [33]. The assessed sub-domains were communication, trust, and alienation. Each item was rated a four-point Likert scale ranging from "strongly disagree" (1 point) to "strongly agree" (4 points), with higher scores indicating a stronger degree of each sub-domain.

\section{Parental factors.}


Parental supervision. Huo's tool [34] was modified and supplemented by Kim et al. [35] in the Korea Institute for Health and Social Affairs' Comprehensive Children's Survey to evaluate parenting behavior using a total of eight items, including four items on praise and encouragement for children. In the PSKC, a total of four items related to parental supervision were used in consideration of the balance with the variables of the previous survey. Responses were provided by the main caregiver and rated on a five-point Likert scale from "strongly disagree" (1 point) to "strongly agree" (5 points).

Parenting behavior. This variable was evaluated using a tool developed by Robinson et al. [36] and modified by PSKC researchers. The tool consisted of three dimensions: authoritative, authoritarian, and permissive parenting behaviors. Authoritative parenting behavior included affection, involvement, reason/induction, democratic relationships, and kindness/comfort. Authoritarian parenting behavior included anger, punishment, and irrational punishment strategies and directives. Lastly, permissive parenting behavior included lack of consistency, neglect, and conviction. The items were evaluated on a five-point Likert scale from "strongly disagree" (1 point) to "strongly agree" (5 points). A higher score indicated higher parenting behavior in each dimension.

\section{Data Collection}

For this secondary data analysis, we requested the Childcare Policy Research Institute for the original national survey data. The purpose of use and researchers' affiliations were explained through the PSKC website. The original data and questionnaire were provided and used in this study.

\section{Data Analysis}

STATA/BE 17 was used for longitudinal analysis of the two-year data. Data from the $10^{\text {th }}$ and $11^{\text {th }}$ years of the survey (2017 to 2018) were case merged using the sample ID. Then, the data were converted to long-type panel data for analysis. Frequency/percentage and mean/standard deviation were calculated to compare subject characteristics and differences between general and risk users. A panel logit model analysis was conducted using STATA/BE 17 to identify factors affecting changes in problematic smartphone users.

If $X_{i t}$ was an independent variable affecting $y_{i t}, u_{i}$ was the intrinsic unobserved heterogeneity of the panel object that does not change with time, and $\varepsilon_{i t}$ was pure error, the regression equation of the panel logit model was as follows:

$y_{i t}=a+\beta^{\prime} X_{i t}+u_{i}+\varepsilon_{i t}$

for $i=1,2, \ldots . ., N$ and $t=1,2, \ldots . ., T$

$\mathrm{N}=$ number of individuals or cross section 
$T=$ number of time periods

A fixed effect and random effect model were estimated sequentially, and the Hausman test was conducted to evaluate the endogeneity problem of explanatory variables. The Hausman test of the panel logit model showed that the null hypothesis, that there was no correlation between individual unobserved heterogeneity and independent variables, was not rejected at a significance level of $5 \%$. Thus, a random effect model was used instead of a fixed effect model $\left(\chi^{2}(13)=(b-B)^{\prime} \square V_{-} b-V_{-} B \nabla^{\wedge}(-1) \rrbracket(b-B)=13.37\right.$, Prob $\left.>\chi^{2}=0.4194\right)$.

\section{Ethical Considerations}

PSKC, the primary data collection institution for this study, was approved by the Korea Institute of Child Care and Education, Institutional Review Board (KICCEIRB-2017-No.05, KICCEIRB-2018-No.02). This data is publicly accessible and written consent was obtained from all participants prior to participating in the survey. The respondent's information was anonymized for research purposes and was not identified prior to analysis. This study was a secondary analysis of publicly available data without state-supplied personal information.

\section{Results}

\section{Demographic and Smartphone-Related Characteristics}

Among 1,286 children aged $9-10$ who participated in the $10^{\text {th }}$ and $11^{\text {th }}$ PSKC, a total of 342 children whose parents and teachers also completed the survey were included in this study. Approximately $50.7 \%$ and $49.7 \%$ of the risk users were boys and girls, respectively, with an almost even gender distribution. Those who lived in small and medium cities, had a monthly household income of $\$ 4,000-\$ 7,000$, had both parents working, and had smartphones were more likely to be risk users. In wave 1 , the daily smartphone usage time of risk users was 1.16 hours, which increased to 1.48 hours in wave 2 (Table 1).

\section{Degree of Problematic Smartphone Use}

Among the 342 subjects, 126 were risk users in wave 1 . In wave 2, the number of risk users increased by $6.8 \%$ to 149 (Table 2).

\section{Differences in Variables Between General and High-Risk Users and Factors Influencing Problematic Smartphone Use}


Table 3 shows the characteristics of general and risk users in waves 1 and 2. A panel logit model analysis was conducted for longitudinal analysis of the effects of problematic smartphone use in preteens (Table 4). Externalization difficulties of preteens (child factor), peer communication (peer factor), and authoritative parenting behavior, permissive parenting behavior, and parental supervision (parental factors) affected problematic smartphone use. Every one-point increase in preteens' externalization difficulties increased the risk of smartphone addiction 3.14-fold (confidence interval (Cl): 1.25-7.87). Every one-point increase in peer communication reduced the risk of smartphone addiction by 0.42 times (Cl: $0.20-0.89$ ). Additionally, every one-point increase in authoritative parenting behavior reduced the risk of smartphone addiction by 0.13 times (Cl: 0.04-0.39) while every one-point increase in permissive parenting behavior increased the risk of smartphone addiction by 6.68 times (Cl: 1.89-23.56). Every onepoint increase in parental supervision reduced the risk of smartphone addiction by 0.41 times $(\mathrm{Cl}: 0.19-$ 0.87).

\section{Discussion}

In this study, authoritative parenting behavior, parental supervision, and peer communication were protective factors for preteens' problematic smartphone use. In contrast, permissive parenting behavior and preteen's externalizing problems were risk factors. These results show that the characteristics of children, parenting and supervision, and peer relationships have complex effects on preteens' excessive smartphone use.

Among the personal characteristics of preteens, externalizing problems were a risk factor for problematic smartphone use. This is in contrast to the findings of a previous study in which internalizing problems such as depression and anxiety were related to excessive smartphone use in adolescents [37]. In adolescents with unstable emotional states, internalizing problems such as anxiety and depression are often associated with overdependence on smartphones [38].. On the contrary, in preteens, externalization problems such as hyperactivity and inattention are more relevant to excessive use of smartphones.

Externalizing and internalizing problems in children and adolescents are observed at the same time as excessive smartphone use. In particular, our finding is similar to that of a previous study showing that difficulties in externalization had longitudinal effects on problematic smartphone use [39]. This suggests the significance of early interventions for preteens' externalizing problems for the prevention of smartphone overuse. In addition, when externalizing problems are observed, smartphone use must be evaluated and monitored.

In this study, the assessment of peer communication was a protective factor for problematic smartphone use. This is in agreement with previous studies reporting that the quality of peer relationships is a protective factor for smartphone overdependence in adolescents [20,40]. Smartphones are used by young age groups as a means of self-expression and communication. They act as a practical tool to satisfy the desire to feel close to peers without spatial and time restrictions [41]. However, preteens who maintain good relationships with their peers in real life are not obsessed with relationships in the virtual world, leading to a low risk of problematic smartphone use [20]. In contrast, preteens who experience 
problems with peer relationships use smartphones excessively to satisfy their desire to have and belong in relationships [42]. A previous study showed that greater peer attachment increases the risk of problematic smartphone use [21], and this is indicated by excessive use of smartphones to not feel isolated from peer groups [43]. Activities such as games and use of social networking sites through smartphones can help preteens expand their networks; however, these superficial activities do not improve the quality of their peer relationships. Preteens learn about their inner emotions and their emotional responses to others, recognize their effects on their peers, and develop stronger relationships through enhanced self-understanding [44]. As peer relationships have effects on smartphone use, which actually acts as means of forming and maintaining relationships, follow-up studies must assess how changes in peer relationships affect smartphone dependence in adolescents and adults.

Our results suggested that authoritative parenting behavior was a protective factor for overdependence on smartphones in preteens. Authoritative parenting behavior can be characterized by affection, involvement, a democratic relationship, and kindness/comfort. Our finding is consistent with that of many previous studies $[22,23,24,45]$. Our finding has a similar context to that of a study where controloriented parenting behavior, contrary to authoritative parenting behavior, increased smartphone use in children [46]. In our study, permissive parenting behavior was a risk factor for problematic smartphone use by preteens. These results are similar to previous findings that smartphone addiction in elementary school children increases when parenting is permissive and neglectful [47] and that emotional neglect by parents increases the risk of excessive smartphone use in children [48]. As parenting behavior has direct effects on smartphone dependence in children, irrational and neglectful parenting behaviors should be avoided, and parenting behaviors leading to the development of a rational and democratic parent-child relationship must be encouraged. Additionally, establishing rules through communication with children would be more effective to guide the appropriate use of smartphones.

Parental supervision was a protective factor for problematic use of smartphones. Parental supervision not only includes monitoring and coercive control over children but also affection and interest in children's daily activities. Appropriate parental control of children's smartphone use has been shown to lower smartphone addiction in children [49]. Such proper parental supervision not only reduces smartphone dependence but also leads children to use smartphones as a means of communication with family rather than for entertainment purposes [50]. Moreover, parental supervision can directly lower children's dependence on smartphones and indirectly as well through self-esteem and peer attachment [51]. As children enter adolescence, peer relations and school and extracurricular activities become more significant. Therefore, parents must be interested in and guide their children's activities rather than seeking to exercise absolute control.

\section{Limitations}

A few limitations must be considered in the interpretation of this study's findings. This study focused on the characteristics of children and interpersonal factors with parents and peers as influencing factors of 
problematic smartphone use in preteens. Therefore, follow-up studies must include more diverse sociological factors such as environmental factors and online regulations and policies. In addition, with problems such as social distancing, limited leisure activities, and a surge in online activities triggered by the coronavirus disease 2019 pandemic, daily changes and cracks in preteens have become more serious. In addition, the daily gap according to the socioeconomic level of households has increased more than before COVID-19, so changes after COVID-19 is necessary to confirm the impact of these changes on smartphone dependence and problematic use.

\section{Conclusion And Implications}

In this study, we identified factors affecting excessive use of smartphones in preteens, whose dependence and risk of problematic use has increased owing to the rapid increase in smartphone usage rates. Previous studies have mostly been cross-sectional, evaluating the correlation between potential risk factors and smartphone addiction. In contrast, the current study utilized a longitudinal design to reflect the changes in and characteristics of children's growth and development. This study is meaningful as it analyzed children, peer, and parental factors. Preteens, who were the subjects of this study, experience a transition from childhood to adolescence. In this period, individuals exhibit the developmental characteristics of both children and adolescents. As a result, a detailed analysis that assesses changes in growth and development is essential for the development of practical interventions. Additionally, longitudinal analysis enables stronger reason-effect inferences, providing a basis for interventions to prevent and manage excessive smartphone use in children and adolescents.

In the current situation where smartphones have become a necessity in children's lives, the present results can help prevent overdependence on smartphones and suggest practical measures for correct use as follows. Parents must not seek to restrict the use of smartphones by force or to have a permissive attitude; instead, they must pay attention to what their children are using smartphones for and how often they do so. The appropriate use of smartphones must be clarified through democratic communication with their children. In addition, if preteens demonstrate externalizing problems such as hyperactivity or inattention, monitoring for smartphone-related problems is required, and early intervention for problem behavior might be needed. In addition, support is needed to improve the quality of peer relationships considering the developmental characteristics of preteens. Forming smooth friendships through communication technology will help prevent problematic use of smartphones.

\section{Declarations}

\section{Ethics approval and consent to participate}

This study was a secondary analysis of publicly available data without state-supplied personal information. PSKC, the primary data collection institution for this study, was approved by the Korea Institute of Child Care and Education, Institutional Review Board (KICCEIRB-2017-No.05, KICCEIRB-2018No.02). Data that cannot be identified by the government were used, and the researcher's affiliation and 
purpose of using the data were identified through the Panel Study on Korean Children website, and data was provided and used. This data is written consent was obtained from all participants prior to participating in the survey. The respondent's information was anonymized for research purposes and was not identified prior to analysis. All methods were performed in accordance with the relevant guidelines and regulations.

\section{Consent for publication}

Not applicable.

\section{Availability of data and materials}

The datasets generated and/or analysed during the current study are available in the $\square$ Panel Study on Korean Children $\otimes$ repository, $\square$ https://panel.kicce.re.kr/pskc/module/rawDataManage/index.do? menu_idx $=56$ [

\section{Competing interests}

The authors declare that they have no competing interests.

\section{Funding}

This work was supported by a 2-Year Research Grant of Pusan National University.

\section{Authors' contributions}

JY, HS and GH presented the idea and developed the theory. JY and HS improved the theory and supervised the study. GH conducted the initial analysis and JY conducted the further analysis. JY drafted the first version of the manuscript. All authors reviewed and approved the final version of the manuscript.

\section{Acknowledgements}

Not applicable.

\section{References}

1. Statista. Number of smartphone users worldwide from 2016 to 2021 (in billions). 2021. https://www.statista.com/statistics/330695/number-of-smartphone-users-worldwide/ 
Accessed 22 Oct 2021

2. Baabdullah A, Bokhary D, Kabli Y, Saggaf O, Daiwali M, Hamdi A. The association between smartphone addiction and thumb/wrist pain: A cross-sectional study. Medicine. 2020; 99(10).

3. Demirci K, Akgönül M, Akpinar A. Relationship of smartphone use severity with sleep quality, depression, and anxiety in university students. Journal of Behavioral Addictions. 2015;doi:10.1556/2006.4.2015.010.

4. National Information Society Agency: Ministry of Science and ICT. https://www.nia.or.kr/site/nia_kor/ex/bbs/List.do?cbldx=65914(2020). Accessed 25 Dec 2021.

5. Chahal H, Fung C, Kuhle S, Veugelers PJ. Availability and night-time use of electronic entertainment and communication devices are associated with short sleep duration and obesity among $\mathrm{C}$ anadian children. Pediatric obesity. 2013;8(1): 42-51.

6. Choi JO. The Impacts of Smartphone Addiction on Academic Grade of Elementary School Students Multiple Mediating Effects of Empathy Impairment \& School Adjustment. Youth Facilities and Environment. 2015;13(2):43-54.

7. Kim EJ. The Effect of Depression, Anxiety, Stress on Self-Esteem and Delinquency Mediated Internet Game Addiction of Elementary Students. The Journal of Elementary Education. 2015;28(3):95-122.

8. Radesky JS, Schumacher J, Zuckerman B. Mobile and interactive media use by young children: the good, the bad, and the unknown. Pediatrics. 2015;135(1): 1-3.

9. Ministry of Gender Equality and Family. Diagnosis of Internet and Smartphone Usage Habits in 2019. http://www.mogef.go.kr. Accessed 12 Nov 2021.

10. Government of Canada. A Child's Age and Stage of Development Make a Difference.2017.https://www.justice.gc.ca/eng/rp-pr/flf/divorce/age/age2c.html. Accessed 20 Dec 2021.

11. Kim KU, Min SH. It's okay if you're not superman. Ministry of Gender Equality and Family $\square$ Korea Institute for Healthy family. http://www.mogef.go.kr (2014). Accessed 19 Aug 2021.

12. Tarullo AR, Obradovic J, Gunnar MR. Self-control and the developing brain. Zero to Three. 2009;29(3): 31-37.

13. Hare TA, Tottenham N, Galvan A, Voss HU, Glover GH, Casey BJ. Biological substrates of emotional reactivity and regulation in adolescence during an Emotional Go-Nogo Task. Biological Psychiatry. 2008; 63(10): 927-934.

14. Kim HS, Seo Mj. The Difference of Ecological Factors According to Cell Phone Dependency and Use Purpose in Cell Phone Users among Children. The Korea Journal of Youth Counseling. 2012; doi:10.35151/kyci.2012.20.2.011

15. Kang KI, Hur SJ, Jo JH. An Integrative Review of Interventions for Internet/Smartphone Addiction among Adolescents. Perspectives in Nursing Science. 2018;15(2):70-80.

16. Lee SH, Cha EJ. Effects of Depression, Self-esteem, and Interpersonal Relationship on Smartphone Overuse in College Students: Based on Health Science Students. Journal of The Korean Data 
Analysis Society. 2014;16(5): 2781-2793.

17. Lee JK, Kang KM. A Meta-Analysis on the Relations Between internal variable, external variable and youth smartphone addiction. Korea Journal of Youth Counseling. 2015;23(1):247-271.

18. Robson DA, Allen MS, Howard SJ. Self-regulation in childhood as a predictor of future outcomes: A meta-analytic review. Psychological Bulletin. 2020;146(4): 324-354.

19. Hawi NS, Samaha M. To excel or not to excel: Strong evidence on the adverse effect of smartphone addiction on academic performance. Computers \& Education. 2016; 98: 81-89.

20. Wang P, Zhao M, Wang X, Xie X, Wang Y, Lei L. Peer relationship and adolescent smartphone addiction: The mediating role of self-esteem and the moderating role of the need to belong. Journal of Behavioral Addictions. 2017;6(4):708-717.

21. Seong YJ. The Impact of the Alienation on Smart-phone Overuse among Youth -the moderating effects of parent attachment and peer attachment(Masters dissertation). 2013;Catholic University of Daegu, Daegu.

22. Kim EH. Structural Relationship among Parental Warmth, Smart-media Dependency, Executive Function Deficit, and Pragmatic Language Ability for Nine-year-old Children. The Journal of LearnerCentered Curriculum and Instruction. 2020;20(7):1037-1059

23. Kim HY, Kim MJ. The Effects of Maternal Parenting Behavior on Children's School Adjustment: The Mediating Effects of Children's Media Device Addiction and Executive Function Difficulty. Korean Journal of Child Studies. 2020;41(1):105-111.

24. Park BK, No JW. Effects of Parenting Behaviors and Children's Happiness on Media Device Addiction. Korean Journal of Child Studies. 2019 40(3):87-103

25. Hong YS, Oh SY. The Influence of Attachment and Monitoring on Adolescent`s Self-control. Journal of Social Science. 2010;16(2):319-336

26. Oh J. A Study on the Major Factors to Teenagers' Addiction to Smart-Phone. The Journal of Public Welfare Administration. 2014;24(1):47-76.

27. Kwon, HW, Lim YJ. The Effects of Parental Attachment Perceived by Upper Grade Elementary School Students on Smartphone Addiction : The Mediating Effects of Smartphone Use Motives. Korean Journal of Youth Studies. 2017;24(9):317-337.

28. National Information Society Agency. 'K-scale (Internet Addiction scale)'. 2019; https://www.iapc.or.kr/kor/PBBS/diaSurvey.do?idx=7. Accessed 12 Sep 2021.

29. MCS. MCS Child Paper Self Completion Questionnaire. 2008; $\square$ Available from: http://www.cls.ioe.ac.uk/page.aspx?

\&sitesectionid=957\&sitesectiontitle=Surveys+and+documentation . Accessed 12 Sep 2021.

30. Rosenberg M. Society and adolescent self-image. Princeton. 1965; NJ: Princeton University Press.

31. Goodman R. The Strengths and Difficulties Questionnaire: a research note. Journal of Child Psychol Psychiatry. 1997; 38(5): 581-586. www.sdqinfo.com. Accessed 12 Oct 2021. 
32. Ji SA, Jeong DH. Validation of School Adjustment Inventory for First Grade Elementary School Students. Korean Journal of Child Studies. 2006; 27(1): 1-15.

33. Armsden GC, Greehberg MT. The inventory of parent and peer attachment:Individual differences and their relationship to psychological well-being in adolescence. Journal of Youth and Adolescence. 1987; 16(5): 427-454.

34. Huo MY. A Study for the Development and Validation of an Inventory for Parenting Behavior Perceived by Adolescents. Korea Journal of Youth Counseling. 2004;12(2): 170-189.

35. Kim MS, Jeon JA, Ha TJ, Kim HJ, Oh MA, Jeong EH, et al. Comprehensive child survey. Korea Institute for Health and Social Affairs; 2013.

36. Robinson CC, Mandleco B, Olsen S F, Hart CH. Authoritative, authoritarian, and permissive parenting practices: Development of a new measure. Psychological reports. 1995; 77(3): 819-830.

37. Jeong B, Lee JY, Kim BM, Park EM, Kwon JG, Kim DJ, et al. Associations of personality and clinical characteristics with excessive Internet and smartphone use in adolescents: a structural equation modeling approach. Addictive Behaviors, 2020; doi:https://doi.org/10.1016/j.addbeh.2020.106485.

38. Zhang YF, Bang MY. Analysis of variables influencing on the addiction tendencies of chinese high school students at-risk for smartphone addiction. Journal of Special Children Education. 2014;16(3):209-226.

39. Poulain T, Vogel M, Kliesener T, Kiess W. Associations between changes in behavioral difficulties and levels of problematic smartphone use in adolescents over a 1-year period. European child \& adolescent psychiatry. 2021; doi: https://doi.org/10.1007/s00787-021-01874-8.

40. Bae SM. The relationships between perceived parenting style, learning motivation, friendship satisfaction, and the addictive use of smartphones with elementary school students of South Korea: Using multivariate latent growth modeling. School Psychology International. 2015; 36(5): 513-531.

41. Olatz LF, Luisa HS, Montserrat FB, Will G. Prevalence of Problematic Mobile Phone Use in British Adolescents. Cyberpsychology, Behavior, and Social Networking. 2014; doi:http://doi.org/10.1089/cyber.2012.0260.

42. Lim JH, Shin KE, Jeon WY. The Influence of Peer Relationship on the Smart Phone Addiction - The Moderating Role of Physical Warmth -. The Korean Psychological Association. 2015; 2015(8): 346.

43. Jang EJ. A Study on the Correlations among the Empathy Ability, Peer Relationships, and Smartphone Addiction of Children: The Mediating Effect of Empathy Ability. Journal of Child Welfare and Development. 2018;16(2):47-66.

44. Hockenberry MJ, Wilson D, Rodgers CC. Essentials of Pediatric Nursing. Mosby: 2018.

45. Yoo SG, Kim JS, Park YJ. The Effects of Parental Attitudes and Mental Health, and School life adjustment on Smartphone Addiction in Elementary School. The Journal of Child Education. 2018;27(2):145-161

46. Lee EJ, Ogbolu Y. Does Parental Control Work With Smartphone Addiction?: A Cross-Sectional Study of Children in South Korea. Journal of Addictions Nursing. 2018; doi:

10.1097/JAN.0000000000000222.

Page $14 / 18$ 
47. Park YS, Lee JH. Effect of Parental Neglect on Mobile Phone Dependency Among Higher Grade in Elementary School Students: Mediating Effects of Social Withdrawal and Self-Esteem. Korean Journal of Child Studies. 2019;40(3):13-26

48. Chen Y, Zhang Y, Zhang L, Luo F, Xu W, Huang J, et al. Childhood emotional neglect and problematic mobile phone use among Chinese adolescents: A longitudinal moderated mediation model involving school engagement and sensation seeking. Child Abuse \& Neglect. 2021; 115: 104991.

49. Gu HY, Kim EJ. Cell Phone Addiction in School-Age Children and Related Factors. Child Health Nursing Research. 2015;21(1):55-63

50. Lim YM. The effects of parental child-rearing attitudes and peer relationships on children`s mobile phone dependency and use type. Korean Journal of Human Ecology. 2014;23(2):163-174.

51. Park JN, Chun JS. The Relationships between Perceived Parenting Attitudes and Mobile Phone Dependency: The Mediating Effects of Self-Esteem. Social Work Practice \& Research. 2013;10:127160 .

\section{Tables}

Table 1

Demographic and Smartphone-Related Characteristics $(N=342)$ 


\begin{tabular}{|c|c|c|}
\hline \multirow[t]{2}{*}{ Variables } & Wave 1 & Wave 2 \\
\hline & $\mathrm{n}(\%)$ or $\mathrm{M}(\mathrm{SD})$ & $\mathrm{n}(\%)$ or $\mathrm{M}(\mathrm{SD})$ \\
\hline \multicolumn{3}{|l|}{ Gender } \\
\hline Boy & $170(49.7)$ & $170(49.7)$ \\
\hline Girl & $172(50.3)$ & $172(50.3)$ \\
\hline \multicolumn{3}{|l|}{ Place of residence } \\
\hline Big city & $139(40.7)$ & $137(40.1)$ \\
\hline Small and medium-sized cities & $178(52.0)$ & $175(51.2)$ \\
\hline Rural area & $25(7.3)$ & $30(8.7)$ \\
\hline \multicolumn{3}{|l|}{ Household income (dollars/month) } \\
\hline$<4,000$ & $149(43.6)$ & $138(40.3)$ \\
\hline$\geq 4,000-<7,000$ & $164(47.9)$ & $170(49.7)$ \\
\hline$\geq 7,000-<9,000$ & $15(4.4)$ & $24(7.0)$ \\
\hline$\geq 9,000$ & $14(4.1)$ & $10(3.0)$ \\
\hline Mother graduated college or high school & $263(77.0)$ & $263(77.0)$ \\
\hline \multicolumn{3}{|l|}{ Mother's working status } \\
\hline Not working & $147(43.0)$ & $133(38.9)$ \\
\hline Working & $195(57.0)$ & $209(61.1)$ \\
\hline \multicolumn{3}{|l|}{ Child's smartphone ownership } \\
\hline No & $125(36.5)$ & $80(23.4)$ \\
\hline Yes & $217(63.5)$ & $262(76.6)$ \\
\hline Time on smartphone (hr/day) & $1.16(0.80)$ & $1.48(0.92)$ \\
\hline
\end{tabular}

Note. M: mean, SD: standard deviation

Table 2

Descrip[A1] tive Problematic Smartphone Use in Preteens $(N=342)$ 


\begin{tabular}{|lllll|}
\hline & & \multicolumn{2}{l|}{ Wave 1} & \\
\cline { 3 - 5 } & & General & Risk & Total \\
\cline { 3 - 5 } & & $\mathrm{n}(\%)$ & $\mathrm{n}(\%)$ & $\mathrm{n}(\%)$ \\
\hline Wave 2 & General & $160(74.1)$ & $33(26.2)$ & $193(56.4)$ \\
\cline { 2 - 5 } & Risk & $56(25.9)$ & $93(73.8)$ & $149(43.6)$ \\
\hline Total & & $216(63.2)$ & $126(36.8)$ & 342 \\
\hline
\end{tabular}

Table 3

Differences in Variables Between the General and High-Risk Groups $(N=342)$

\begin{tabular}{|lllll|}
\hline Variables & Wave 1 & & Wave 2 & \\
& General & Risk & General & Risk \\
& M (SD) & M (SD) & M (SD) & M (SD) \\
\hline Overall happiness & $3.38(0.44)$ & $3.27(0.45)$ & $3.40(0.46)$ & $3.23(0.46)$ \\
\hline Self-esteem & $3.53(0.40)$ & $3.47(0.42)$ & $3.54(0.46)$ & $3.45(0.44)$ \\
\hline Strengths and difficulties & & & & \\
\hline Internalizing problems & $1.27(0.28)$ & $1.30(0.30)$ & $1.63(0.24)$ & $1.67(0.24)$ \\
\hline Externalizing problems & $1.29(0.31)$ & $1.38(0.35)$ & $1.84(0.28)$ & $1.96(0.33)$ \\
\hline Prosocial behavior & $2.53(0.48)$ & $2.43(0.50)$ & $2.60(0.43)$ & $2.43(0.48)$ \\
\hline School adjustment & $4.20(0.71)$ & $3.99(0.72)$ & $4.28(0.65)$ & $4.02(0.69)$ \\
\hline Peer attachment & & & & \\
\hline Communication & $3.16(0.55)$ & $3.02(0.58)$ & $3.19(0.55)$ & $3.01(0.50)$ \\
\hline Trust & $3.26(0.60)$ & $3.14(0.65)$ & $3.30(0.62)$ & $3.13(0.58)$ \\
\hline Isolation & $1.97(0.62)$ & $2.03(0.66)$ & $1.83(0.54)$ & $1.90(0.58)$ \\
\hline Parental supervision & $4.77(0.35)$ & $4.59(0.47)$ & $4.71(0.40)$ & $4.57(0.46)$ \\
\hline Parenting behavior & & & & \\
\hline Authoritative & $3.94(0.38)$ & $3.72(0.30)$ & $3.95(0.33)$ & $3.75(0.38)$ \\
\hline Authoritarian & $2.29(0.43)$ & $2.44(0.45)$ & $2.22(0.44)$ & $2.41(0.42)$ \\
\hline Permissive & $2.40(0.27)$ & $2.54(0.28)$ & $2.29(0.32)$ & $2.47(0.31)$ \\
\hline
\end{tabular}


Note. M: mean, SD: standard deviation 